\title{
Androgen Insensitivity Syndrome: Drawbacks of the Medical Services
}

\author{
Lukman Yusuf* and Shiferaw Negash \\ Department of Obstetrics and Gynecology, College of Health Sciences, School of Medicine, Ethiopia
}

*Corresponding author: Lukman Yusuf, Department of Obstetrics and Gynecology, College of Health Sciences, School of Medicine, Ethiopia

\section{ARTICLE INFO}

Received: 㓞 November 19, 2019

Published: November 26, 2019

Citation: Lukman Yusuf, Shiferaw Negash. Androgen Insensitivity Syndrome: Drawbacks of the Medical Services. Biomed J Sci \& Tech Res 23(2)-2019. BJSTR. MS.ID.003873.

Keywords: Androgen Insensitivity Syndrome; Addis Ababa; Ethiopia

Abbreviations: AIS: Androgen Insensitivity Syndrome; TFS: Testicular Feminization Syndrome; CAIS: Complete Androgen Insensivity Syndrome; PAIS: Partial Androgen Insensivity Syndrome; MAIS: Mild Androgen Insensivity Syndrome; ERT: Estrogenic Placement Therapy; AR: Androgen Receptor; SBMA: Spinal Bulbar Muscular Atrophy; MIF: Mullerian Inhibitory Factor; TDS: Testicular Determining Factor

\section{ABSTRACT}

Androgen Insensitivity Syndrome (Testicular Feminization Syndrome, Morris syndrome), except for occasional spontaneous mutations, is an X-linked recessive genetic disorder that markedly influences sexual development in utero, during puberty and beyond with significant degree of feminization and reciprocally undermusculinzation of the extertnal genitalia. They usually have external female sex characteristics, male or ambiguous sex development. They do not have ovaries and the Mullerian structures that include the tubes, uterus, cervix and upper part of the vagina. Therefore, they do not ovulate nor gestate and bear a child contrary to the expectation of otherwise a phenotypically full-blown woman.

These case reports initially presented with complaints of female sexual dysfunction with their partners failing to perform deep penetrative vaginal sexual intercourse and the personal inability of the alleged women to menstruate and also achieve a clinically verified pregnancy. With the exception of the only male patient with MAIS ( Mild Androgen Insensitivity Syndrome) with male sexual dysfunction, infertility and gynaecomastia, their sex of rearing was as women and their phenotypic presentations was like women although in retrospect their broad shoulders, medium to tall statures, ambiguous external genitlia and coarse skinfolds could trigger a rise in one's eye brows in line with a disorder of sex development. They were married to men as females just to find out during their workup, short of the social sex, that the Y chromosome was present and their Karyotype XY, negative for Barr bodies and that they are genotypically males with Androgen Insensitivity Syndrome. In a country like ours where marriages are usually arranged at family level, the inadvertent same sex consensual marriages may remain unnoticed, undiagnosed and contributing to marital disharmony and breakdowns.

In addition to the CAIS (Complete Androgen Insensitivity Syndrome) cases, we shall also include the only MAIS obese, inferile male client with severe gynaecomastia and a micropenis. No such cases have been published in Ethiopia and this presentation will illucidate the pitfalls of the medical services vis-à-vis the psychosocial and psychosexual orientation of the population and the available medical services.

\section{Introduction}

The normal embryological development, anatomical structural setup and physiological functionality of the genital system and the germ cells developments assures and ensures the perpetuation of the human species. The sex of an individual is genetically predestined at the time of fertilization and its development is critical between 8-14 weeks of gestation in utero. If, however, the interplay of the chromosomal, chromatin and gonadal sexes are not fully and properly expressed, the alternatives of sex assignment may assume that of the sex of rearing and phenotypic appearance (social sex) of the individual [1-7].

It is not an uncommon societal practice in Ethiopia to assign sex of the opposite gender, out of shear desire of the family, when the offspring are repetitively of the same sex. Their hairdos, dressings and behaviours tend to simulate the assigned sex and 
are addressed as a she-woman in case of a male and a he-man if a girl. It is a traditional practice that does not entail discrimination, stigmatization, abuses or legal challenges. The reversal of roles usually resumes and normalise after puberty. Androgen Insensitivity syndrome (AIS), the largest single entity which is a rare sex-linked recessive inheritance formerly referred to as Testicular Feminization Syndrome (TFS) or Morris syndrome is a form of a disorder of sex development that results in a complete or partial inability of the body cell to respond to the male hormone, androgens. It thus occurs in more frequently with phenotypically women segment of the population with well-developed secondary sex characteristics that includes normal breast development, normal or ambiguous external genitalia, a vagina of variable depth, absent uterus, sparse or absent pubic and axillary hair. Thus, the testes do not normally develop and function like a male and the individual will develop female genital organs whether the ovaries are present or not, thereby depicting the female sex as a neutral sex. The male testes could be abdominal, inguinal or labial in locations and functionally will be redundant and not expressed as a male. The penis does not form or is underdeveloped (micropenis), and the child may appear female or end up with an ambiguous external genitalia $[5,7,8]$.

AIS is divided into three categories that includes CAIS with the external genitalia being complete female and testosterone has no effect on the sexual development whereas PAIS (Reifenstein Syndrome) with sparse or absent pubic and axillary hair is partially or not fully masculinized individual with a very likelihood of a typical female or male or an ambiguous genitalia. Their gender identity shall be reflected by the sex assignment and/or their sex of rearing. The very rare form of AIS, MAIS, is described with external genitalia with a micropenis, hypospadias, epispadias and more of a typical male feature but develop gynaecomastia at puberty. The incidence of an AIS is 1:20,000-64,0000 male births, while the incidences are low and highly variable for Complete Androgen Insensivity Syndrome (CAIS) i.e 1 in 20,400, 1 in 99,100, 1 in 2000,1 in $6240046 \mathrm{XY}$ live births as opposed to Partial Androgen Insensivity Syndrome (PAIS) of 1 in 130,000 46 XY births while the true incidence of Mild Androgen Insensivity Syndrome (MAIS) is not known [9-12]. We have chosen these case presentations as an entry point to highlight on such a disorder of sex development and demonstrate the draw backs in the medical services and subsequent management difficulties.

\section{Case 1}

A YT is a 48 years old female resident of Addis Ababa. She is very tall by an Ethiopian standard (178, weight $95 \mathrm{Kg}$ ) and sturdy presenting with a complaint of primary amenorrhoea and dyspareunia. She is intelligent, calm, communicative, transparent and accepting and living with her condition. Academically and professionally, she has a well achieved position with an executive status. On physical examination, she was found out to have coarse skin, big breasts, sparse axillary and pubic hair distributions. She has poorly developed labia, a vaginal pouch of about $4 \mathrm{~cm}$ and no cervix is noted upon speculum inspection nor is there a palpable cervix behind the apex of the septum on bimanual pelvic or rectal examinations.

All laboratory investigations including haematology, organ function tests, FBS, lipid profile, fertility panel, HBsAG, HCV antibody, VDRL, TPHA and HIV screening were unremarkable. A transvaginal ultrasound revealed no uterus and the ovaries were not appreciated. MRI of the pelvis and lower abdomen confirmed the absence of the uterus and ovaries; and established a colonic mass along with bilateral intraabdominally located testes. The Barr body for chromatin sex and chromosomal sex determination reported and elaborated that it is negative for Barr bodies and the karyotype appears to be 46XY.Y chromosome is present. The SRY region did not show significant anomaly. The sex reversal genes as well as those individuals in gonadogenesis did not show significant anomaly. The CYP21A2 gene was associated with CAH did not show significant alterations, however the copy number change observed on the adjacent gene TNBX and the ambigious copy number changes suggest anomaly that pertains to $46 \mathrm{XY}$ virilization. Rectosigmoidoscopy and biopsy of the rectosigmoid mass established colon cancer. Accordingly, surgical treatment for the colon cancer and gonadectomy for the testes were emphatically recommended and patient preferred to go abroad for the surgery.

\section{Case 2}

This relates to an SN of 38 years of age who was married twice as a female. She is of short stature with a height of $165 \mathrm{~cm}$ and body weight of $73 \mathrm{Kg}$. She presented with a complaint of primary amenorrhoea and difficulty in attaining proper vaginal penetrative sexual intercourse which was also the actual reason for the divorce with the first husband. Elevated LH, serum testosterone of $33.05 \mathrm{nmol} / \mathrm{l}$ (normal range $0.25-2.75 \mathrm{nmol} / \mathrm{L}$ ) with no virilization, and AMH or Mullerian inhibiting substance of $>23.5 \mathrm{ng} / \mathrm{ml}(0.03-7.15 \mathrm{ng} / \mathrm{ml})$ as an instrument to evaluate ovarian reserve, development of sex disorder with ambiguous genitalia and testicular function were very impressive in this particular patient. All other laboratory investigations were within normal limits.

The abdominal and transvaginal ultrasonography by the radiologists in collaboration with us concluded that the uterus was absent, and no adnexal masses were noted but failed to localize the testes. The radiologists recommended an MRI for a thorough abdominopelvic study. A very tedious and very challenging, extensive MRI examinations, free of charge and out of interest, carried out and reported that the uterus is not visualized, that there is questionable lower vaginal canal with upper $2 / 3 \mathrm{rd}$ obliterated. There is $1.9 \mathrm{~cm} \times 1.4 \mathrm{~cm}$ measuring right pelvic and left pelvic $2.2 \mathrm{~cm} \times 2.1 \mathrm{~cm}$ ovoid structures seen medial to the external ileac vessels near S1 and S2 levels bilaterally. The structure show diffusion restriction. There is $1.4 \mathrm{~cm} \times 1.5 \mathrm{~cm}$ measuring T2 
hyperintense lesion near the left ovoid structures posteriorly as suggestive of remnants of Wolffian derivatives.

The conclusion/interpretation of the chromatin and chromosomal study showed that the subtelometric screening did not how significant copy number changes and does not suggest ploidy error. Y chromosome is present though the sex was reported as female. The SRY region seem to be intact. The AR gene does not show significant anomaly. The karyotype appears to be 46XY. The other investigated genes and chromosomal regions also did not show significant anomaly. It was a bombshell for her to be told of the details. She was referred to a psychiatrist, who was briefed on the condition of AIS. Upon the psychiatric consultation, she showed no sign of depression and hopelessness. She was further counselled on the need to undergo gonadectomy and that it may be beneficial to regularly perform vaginal dilatation with a dilator of average penile length and continue taking hormone replacement therapy in a form of estrogenic placement therapy (ERT).

\section{Case 3}

This is a 45 years old married male individual, MA, from a neighbouring country, accompanied by family members, presented with a complaint of infertility of three years duration. Upon physical examination it was observed that he was short stature and of $160 \mathrm{~cm}$, obese $(80 \mathrm{~kg})$ slow in his reactions may be because of the in-between interpreter. It was revealed that he had bilateral huge gynaecomastia, a micropenis, inguinal hernia and bilateral undescended testes. He had no neuromuscular deficits unlike Kennedy's disease which is characterized by Spinal Bulbar Muscular Atrophy (SBMA). He was diagnosed to suffer of Mild Androgen Insensitivity Syndrome. He was azoospermic. The hormone concentrations are normal and all the laboratory investigations other than those mentioned were non-revealing the ultrasonography confirmed right intra-abdominal testis and left inguinal testis with inguinal hernia containing small bowel loops. A right-sided retroperitoneal mass with invasion of the right renal hilum was also diagnosed. The karyotyping appears to be $46 \mathrm{XY}$. WNT4 upregulate NROBI, which influences the sex determination. The AR, CAH related CYP21A2 and the gonadogenesis related genes did not show significant copy number changes. The WNT4 copy number change is the only genetic alteration that can be detected by MLPA, and which might explain the clinical scenario. However, subtle changes such as point mutations and balanced translocation and other genetic changes that cannot be detected by the method employed cannot be ruled out. The case was discussed quite thoroughly with the family members and demonstrated the immediate physical abnormalities as per his consent and strong desire of the companions. It was then recommended that he should be on testosterone long term therapy, possibly undergo mastectomy, herniorrhaphy and gonadectomy of the left atrophied inguinal testis and of the right abdominal to minimize the risk of malignancy. Moreover, it was stressed and underlined to all for the need for explorative laparomy for the alleged invasive retroperitoneal tumour.

\section{Discussion}

Androgen Insensitivity Syndrome is a genetic disorder that makes XY foetuses in utero and later in life unresponsive to the androgen, dihydrotestosterone. Externally they look like normal girls/females but internally they have a short, blind-pouch of vagina and no uterus, ovaries and fallopian tubes as well as the Testicular Determining Factor (TDS), Mullerian Inhibitory Factor (MIF) are not expressed and were never operational. Hence, there is a disconnection between chromosomal, chromatin, gonadal, phenotypic social sex and sex of rearing of the family making it interesting and worth bringing the topic forth and subject it for discussion from our perspective. As in our subjects, they are sterile as they lack the structures, being incapable of contributing an egg towards conception or inherently experiencing impaired spermatogenesis and hence not capable of gestating of own or surrogate a child of others $[13,14]$.

A prenatal sex determination that was suggestive of an $\mathrm{XY}$ Karyotype with an external female genitalia at birth should strengthen the suspicion of a disorder of sex development. The lack of conduct of a routine neonatal physical assessment at birth, in particular of the external genitalia, inguinal hernia with a coexistent testis in the hernial sac or within the labia, and entering the findings in the indivdual document markedly contributes to a cascade of management difficulties of a cluster of such patients in the course of time. Early assignment of sexes or in cases of ambiguity, as in PAIS, posponing it for a later appropriate date in accordance with the developmental milestones including the onset of menarche remains to be the pure responsibility of the care givers at birth and early neonatal health care service providers whether paediatricians or gynaecologists [12,15-20].

Primary amenorrhoea at puberty, the absence of pubic and axillary hair, no temporal balding and coarseness of the skin texture may herald the likelihood of the presence of a disorder of sex development. In the best interest of parents and specialists, paediatric age groups ought to be examined and make sure that such disorders are excluded. We were not very much impressed with the height and weight of the patients since only one of them was noticeably tall and sturdy.

If premarital and preconeptional counselling coupled with commensurate physical examinations are provided, the painful and complicated aftermath of the conflict of sex identity and dysphoria that are embarrassing or distressful which is actually the situation among our patients. It is as such vey preventable or else easily and timely ameliorated in accordance with the life expectancy of the individuals instead of addressing it as such at the late third or fourth decades of life whereby they have already lived their two thirds of life. 
The diagnosis of AIS is basically reached at by exclusion of other causes and hence the clinical and supplementary laboratory investigations as in our subjects remain the gold standard for the eventual diagnosis. The presence of a short vagina, under masculinized genitalia, partial or complete regression of Múllerian structures, bilateral nondysplastic testes, impaired spermatogenesis and/or normative virilization should be able to raise the suspicion of the diagnosis of AIS. The laboratory determination of the $46 \mathrm{XY}$ Karyotype chromosome or Barr bodies yields coupled with typical normal or elevated testosterone values, follicle stimulation and luteinizing hormones and oestradiol levels ultimately will complete the investigations and strengthen the diagnosis $[7,11,15,20]$.

The management of such patients is basically symptomatic. It should address the functional, sexual and psychological aspects of AIS. The mutated and malfunctioning androgen receptor (AR) gene located on the proximal long arm of the $\mathrm{X}$ chromosome persists as a sex-linked recessive affecting $50 \%$ of the female off springs of the mother and could not be as such altered and hence genetic advice becoming more mandatory and carrier testing a necessity. A multidisciplinary approach is beneficial in terms of both optimum clinical management and education of the health-care professionals. Treatment ought to be highly individualized, holistic, flexible, long term and passionate so that such individuals are not neglected and under diagnosed. It is the Chicago Consensus that discarded the term intersex in favour of the term disorder of sex development and reached at a consensual management strategy in order to avoid such pitfalls [1,21-23].

The challenges of sex assignment when not matched by the gender identity, the clients develop gender dysphoria and prefer to live as a member of the opposite sex and look for comparable treatment modalities accordingly but if dealt with as much a younger age and should not be so belated. Mastectomy in MAIS and gonadectomy of the cryptorchid testes to minimize future and more feared malignant tumour risk or orchipexy when feasible and thought beneficial should be offered to the individuals. It is to be stressed that if gonadectomy was not done in infancy, it is generally recommended in early adulthood to avoid the risk of gonadal tumours of $30 \%$ in late adulthood with a general risk range of $0-22 \%$. In our cases one underwent orhidectomy while the second one hashed and even abandoned the psychiatric consultation after one single session. Generally, disclosure and subsequent hormone replacement, genitoplasty in terms of creation of a functional vagina if no indentation or pouching, dilator therapy after surgery or constant usage of vaginal dilators may be warranted and provided to the patients. It was not an easy undertaking in our situation as sexuality is very much self-contained, not expressed in any form at its highest level from rights perspective and as such difficult to manage as was the case in our patients $[9,10,16,24,25]$.

Clitoral length and width are shorter in CAIS because of the absence of prenatal and postnatal action of androgens. A monthly testosterone injection may be useful when given especially for MAIS cases under the assumption that it may improve their spermatogenesis and male sexual function. Sex hormone at pubery and beyond for the females should be provided in a form of estragon replacement therapy as they are predisposed for osteoporosis and ethinylestradiol of 2 ug daily from 11 years onward with incremental doses to reach to a daily dose of $30 \mathrm{ug}$ is a well thought of approach [26,27]. Genetic counselling is essential and psychological support and openness in disclosure as part of a multipronged multidisciplinary approach is highly advocated. The focused and highly individualized management scheme is the central theme to be strived at but above all the diagnosis should never come so late.

\section{Acknowledgement}

We are deeply indebted to Dr Yonas Tadesse and Dr Alemayehu Bedane, senior cosultant radiologists, who were interested in the cases, performed the ultrasononography and MRI untiringly and without charging the patients on all repeat studies upuntil the final diagnoses were established. Our heartfelt thanks go to MRCET Advanced Laboratory for availing the tests and the Senior Technologist /Molecular Geneticists who conducted the tests.

\section{References}

1. Hughes IA, Davies JD, Bunch TI, Pasterski V, Mastroyannopoulou K, et al. (2012) Androgen Insensitivity Syndrome. Lancet 380(9851): 14191428.

2. Mongan NP, Tadokoro-Cuccaro, Bunch TI, Hughes IA (2015) Best Pract Res Clin Endocrinol Metab 29(4): 569-580.

3. Quigley CA, De Bellis A, Marschke KB, Mostafa K El-Awady, Elizabeth M Wilson, et al. (1995) Androgen receptor defects: historical, clinical, and molecular perspectives. Endocr Rev 16(3): 271-321.

4. Zuccarello D, Ferlin A, Vinanzi C, Prana E, Garolla A, et al. (2008) Detailed functional studies on androgen receptor mild mutations demonstrate their association with male infertility. Clin Endocrinol 68(4): 580-588.

5. Achermann JC, Jameson JL (2006) Disorders of sexual differentiation. Harrison's endocrinology. New York: McGraw-Hill Medical Pub. Division pp. 161-172.

6. Medonca BB, Gomes NL, Costa EM, Inacio M, Martin RM, et al. (2017) $46, \mathrm{XY}$ disorder of sex development (DSD) due to 17B-hydroxysteroid dehydrogenase type 3 deficiency. J Steroid Biochem Mol Biol 165(PtA): 79-85

7. Mendonca BB, Domenice S, Arnhold IJ, Costa M (2009) 46,XY disorders of sex development (DSD). Clin Endocrinol (Oxf) 70(2): 173-187.

8. Hannema SE, Scott IS, Rajpert-De Meyts E, Skakkebaek NE, Coleman N, et al. (2006) Testicular development in the complete androgen insensitivity syndrome. J Pathol 208(4): 518-527.

9. Zorlu F, Cengiz M, Gurkaynak M (2001) Seminoma arising in androgen (insensitivity syndrome): a case report. Turk J Cancer 1: 168-171.

10. Gurer IE, Demirkiran AE (2000) Sertoli cell tumor in two sibs with testicular feminization syndrome. Turk J Med Sci 30: 385-387.

11. Oakes MB, Eyazzadeh AD, Quint E, Smith YR (2008) Complete androgen insentivity syndrome-a review. J Petiatr Adolesc Gynecol 21(6): 305310 .

12. Mazen I, El-Ruby M, Kamal R, El-Nekhely I, El-Ghandour M, et al. (2010) Screening of genital anomalies in newborns and infants in two Egyptian governorates. Horm Res Paediatr 73(6): 438-442. 
13. Hughes IA, Werner R, Bunch T, Hiort O (2012) Androgen Insensitivity Syndrome. Semin Reprod Med 30(5): 432-442.

14. Simpson JL, Rebar RW, Hung, Wellington, Becker (2002) Principles and Practice of Endocrinology and Metabolism. Hagerstwon, MD: Lippincott Williams \& Wilkins pp. 852-885.

15. Hughes IA, Deeb A (2006) Androgen resistance. Best Pract Res Clin Endocrinol Metab 20(4): 577-598.

16. Carmina E (2006) Mild androgen phenotypes. Best Pract Res clin Endocrinol Metab 20(2): 207-220.

17. Bouvattier $C$, Mignot $B$, Lefèvre $H$, Morel $Y$, Bougnères $P(2006)$ Impaired sexual activity in male adults with partial androgen insensitivity. J Clin Endocrinol Metab 91(9): 3310-3315.

18. Chiu RW, Lo YM, (2011) Non-invasive prenatal diagnosis by fetal nucleic acid analysis in maternal plasma: the coming of age. Semin Fetal Neonatal Med 16(2): 88-93.

19. Yalinkaya A, Yayla M, Erdemoglu M (2007) Prenatal diagnosis of a fetus with androgen insensitivity syndrome (AIS). Prenat Diagn 27(9): 856857.

20. Pérez-Palacios G, Chávez B, Méndez JP, McGinley JI, Ulloa-Aguirre A (1987) The syndromes of androgen resistance revisited. J Steroid Biochem 27(4-6): 1101-1108.

21. Brain CE, Creighton SM, Mushtaq I, Carmichael PA, Barnicoat A, et al. (2010) Holistic management of DSD. Best Pract Res Clin Endocrinol Metab 24(2): 335-354

ISSN: 2574-1241

DOI: 10.26717/BJSTR.2019.23.003873

Lukman Yusuf. Biomed J Sci \& Tech Res

(c) (9) This work is licensed under Creative

Submission Link: https://biomedres.us/submit-manuscript.php
22. Douglas G, Axelrod ME, Brandt ML, Elizabeth Crabtree, Jennifer E. Dietrich, et al. (2010) Consensus in guidelines for evaluation of DSD by the Texas Children's Hospital Multidisciplinary Gender Medicine Team. Int J Ped Endocrinol 919707.

23. Houk CP, Lee PA (2012) Update on disorders of sex development. Curr Opin Endocrinol Diabetes Obes 19(1): 28-32.

24. Ismail-Pratt IS, Bikoo M, Liao LM, Conway GS, Creighton SM (2007) Normalization of the vagina by dilator treatment alone in Complete Androgen Insensitivity Syndrome and Mayer-Rokitansky-Kuster-Hauser Syndrome. Hum Reprod 22(7): 2020-2024.

25. Ozülker T, Ozpaçaci T, Ozülker F, Ozekici U, Bilgiç R, et al. (2010) Incidental detection of Sertoli-Leydig cell tumor by FDG PET/CT imaging in a patient with androgen insensitivity syndrome. Ann Nucl Med 24 (1): 35-39.

26. Illig R, DeCampo C, Lang-Muritano MR, Prader A, Torresani T, et al (1990) A physiological mode of puberty induction in hypogonadal girls by low dose transdermal 17 beta-oestradiol. Eur J Pediatr 150(2): 86-91.

27. Danilovic DLS, Correa PHS, Costa EMF, Melo KFS, Mendonca BB, et al. (2007) Height and bone mineral density in androgen insensitivity syndrome with mutations in the androgen receptor gene. Osteoporos Int 18(3): 369-374

$\begin{array}{ll}\text { BIOMEDICAL } & \text { Assets of Publishing with us } \\ \text { RESEARCHES } & \text { - Global archiving of articles } \\ & \text { - Immediate, unrestricted online access } \\ & \text { - Rigorous Peer Review Process } \\ & \text { - Anttps://biomedres.us/ }\end{array}$

